\title{
Atypical femoral fracture
}

\author{
Aliya Aziz Khan MD, Stephanie Kaiser MD
}

Cite as: CMAJ 2017 April 10;189:E542. doi: 10.1503/cmaj.160450

\section{Atypical femoral fracture is an uncommon complication of long- term use of bisphosphonates}

Long-term use of bisphosphonate is defined as greater than three years for the treatment of osteoporosis. ${ }^{1}$ This type of fracture accounts for $1.1 \%$ of all femoral fractures, with an age-adjusted incidence rate of 1.8 to 113 cases per 100000 personyears for bisphosphonate exposure of less than 2 years to $8-10$ years, respectively. ${ }^{1}$ Number needed to harm is about 1 per 2000 per year of bisphosphonate use. ${ }^{2}$ Atypical femoral fractures can occur in the absence of osteoporosis treatment.

\section{Atypical femoral fractures are stress or insufficency fractures occurring in the femoral shaft}

Bisphosphonates inhibit osteoclasts and decrease bone remodelling that may lead to accumulation of microdamage and stress fracture in the femoral shaft (below the lesser trochanter and proximal to the supracondylar flare; Figure 1A).1,3

\section{3}

\section{Prodomal thigh or groin pain may occur before fracture}

In about $70 \%$ of patients, pain in the thigh or groin may be present for several weeks or months before the atypical femoral fracture occurs. ${ }^{1}$ Patients receiving long-term antiresorptive treatment (e.g., bisphosphonates or denosumab) who have thigh or groin pain should undergo full-length plain radiography of both femurs. If a stress fracture is not found, the patient should be referred for further imaging (i.e., bone scan or magnetic resonance imaging). ${ }^{4}$

\section{Atypical femoral fracture may first present as an incomplete fracture}

Incomplete fracture is seen on radiography as an area of cortical thickening (Figure $1 \mathrm{~B}$ ) and is bilateral in up to $63 \%$ of cases. ${ }^{5} \mathrm{An}$ incomplete atypical femoral fracture can progress and become complete across the femur shaft. ${ }^{1}$ Minimal comminution is typical, with a short oblique or horizontal fracture line. ${ }^{4} \mathrm{~A}$ medial spike may also be apparent. ${ }^{4}$

\section{Antiresorptive treatment should be stopped after a diagnosis of 2 complete or incomplete atypical fracture}

Weight bearing should be limited for patients with incomplete atypical femoral fractures and guided by the presence of thigh or groin discomfort. Management includes intramedullary nailing. ${ }^{4}$ Teriparatide, an anabolic agent, has been associated with healing of atypical femoral fracture in some cases. ${ }^{4}$

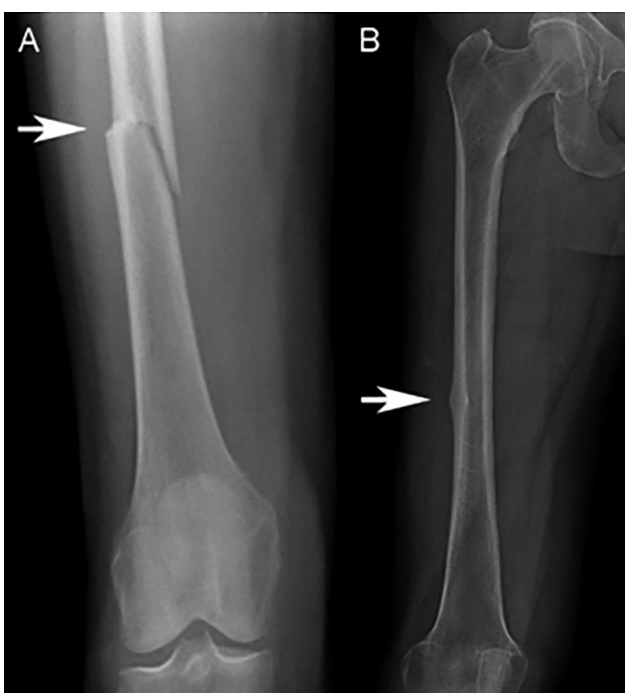

Figure 1: Radiographic views of (A) an atypical femoral fracture that occurred spontaneously in a woman after six years of treatment with a bisphosphonate and (B) an incomplete atypical femoral fracture with cortical thickening that presented as thigh pain.

\section{References}

1. Shane E, Burr D, Abrahamsen B, et al. Atypical subtrochanteric and diaphyseal femoral fractures: second report of a task force of the American Society for Bone and Mineral Research. J Bone Miner Res 2014;29:1-23.

2. Schilcher J, Michaelsson K, Aspenberg P. Bisphosphonate use and atypical fractures of the femoral shaft. NEngl J Med 2011;364:1728-37.

3. Adler RA, El-Hajj Fuleihan G, Bauer DC, et al. Managing osteoporosis in patients on long-term bisphosphonate treatment: report of a task force of the American Society of Bone and Mineral Research. J Bone Miner Res 2016;31:16-35.

4. Khan AA, Leslie WD, Lentile B, et al. 2014. Atypical femoral fractures. a teaching perspective. Can Assoc Radiol J 2015;66:102-7.

5. Probyn L, Cheung AM, Lang C, et al. Bilateral atypical femoral fractures: How much symmetry is there on imaging? Skeletal Radiol 2015;44:1579-84.

\begin{abstract}
Competing interests: Stephanie Kaiser has received grants from Amgen and Eli Lilly Canada, and speaker fees from Amgen and Merck. Aliya Khan has received research funds from Amgen, Merck and Shire.
\end{abstract}

This article has been peer reviewed.

Affiliations: Divisions of Endocrinology and Medicine, and Geriatric Medicine (Khan), Department of Medicine, McMaster University, Oakville, Ont.; Nova Scotia Health Authority, and Division of Endocrinology \& Metabolism (Kaiser), School of Health and Human Performance, Dalhousie University, Halifax, NS

Correspondence to: Aliya Khan, draliyakhan@gmail.com 